И в коже больных бляшечным псориазом

Пашкин А. Ю. ${ }^{1}$, Жуков А. С. ${ }^{2}$, Хайрутдинов В. Р. ${ }^{2,}$, Белоусова И. Э. ${ }^{2}$, Самцов А. В. ${ }^{2}$, Гарабаджиу А. В. ${ }^{3}$

\author{
13-й военный госпиталь войск национальной гвардии Российской Федерации \\ 192171, Российская Федерация, г. Санкт-Петербург, ул. Цимбалина, д. 36 \\ ${ }^{2}$ Военно-медицинская академия им. С. М. Кирова Министерства обороны Российской Федерации \\ 194044, Российская Федерация, г. Санкт-Петербург, ул. Академика Лебедева, д. 6 \\ ${ }^{3}$ Санкт-Петербургский государственный технологический институт (технический университет) \\ 190013, Российская Федерация, г. Санкт-Петербург, Московский просп., д. 26
}

B настоящее время установлено, что цитокины семейства IL-36 занимают значимое место в инициации и регуляции воспалительного процесса при псориазе.

Цель: изучение уровня экспрессии цитокинов IL-36y в коже пациентов с бляшечным псориазом. Материал и методы. Исследовали биоптаты кожи 31 пациента с бляшечным псориазом. Группу сравнения составили по 20 биоптатов кожи больных ограниченным нейродермитом, нуммулярной экземой, красным плоским лишаем, грибовидным микозом (бляшечная стадия). В качестве группы контроля изучали биоптаты кожи 10 здоровых человек. Проведено иммуногистохимическое исследование кожи с использованием anti-IL-36y антител.

Результаты. Установлено увеличение относительной площади экспрессии IL-36y в пораженной коже пациентов с бляшечным псориазом (7,4 \%) по сравнению с непораженными участками (0,10 \%) и группой контроля (0 \%). Экспрессия IL-36ү в коже больных псориазом в прогрессирующем периоде (8,85 \%) была в 1,42 раза выше, чем в стационарном периоде заболевания (6,2 \%). Выявлена сильная прямая связь $(r=0,71)$ между уровнем экспрессии IL-36ү в пораженной коже и значением индекса PASI, умеренная прямая связь между уровнем экспрессии IL-36ү и толщиной эпидермиса $(r=0,34)$. В пораженной коже больных псориазом отмечалась выраженная экспрессия IL-36y в верхних слоях эпидермиса, у пациентов группы сравнения (экзема, нейродермит, красный плоский лишай, грибовидный микоз) - слабая или умеренная, в непораженных участках кожи больных псориазом и здоровых людей - слабая или отсутствовала.

Выводы. Установлено, что экспрессия IL-36y в коже пациентов с бляшечным псориазом значительно выше, чем при других заболеваниях кожи. Полученные данные позволяют рассматривать этот цитокин в качестве возможного диагностического маркера и использовать его при проведении диффреренциальной диагностики.

Ключевые слова: бляшечный псориаз, ограниченный нейродермит, красный плоский лишай, нуммулярная экзема, грибовидный микоз, интерлейкин-36ү

Конфрликт интересов: авторы заявляют об отсутствии потенциального конфликта интересов, требующего раскрытия в данной статье.

Для цитирования: Пашкин А. Ю., Жуков А. С., Хайрутдинов В. Р., Белоусова И. Э., Самцов А. В.,

Гарабаджиу А. В. Исследование уровня экспрессии интерлейкина-36у в коже больных бляшечным псориазом. Вестник дерматологии и венерологии. 2019;95(4):31-39. https://doi.org/10.25208/0042-4609-2019-95-4-31-39 


\title{
Studying of the interleukin-36y expression level in the skin of patients with plaque psoriasis
}

\author{
Alexey Yu. Pashkin ${ }^{1}$, Alexander S. Zhukov², Vladislav R. Khairutdinov², , Irena E. Belousova²,
} Alexey V. Samtsov², Alexander V. Garabagiou ${ }^{3}$

${ }^{1}$ The $3 \mathrm{~d}$ Military Hospital, National Guard Forces

Tsimbalina str., 36. Saint Petersburg, 192171, Russian Federation

${ }^{2}$ S. M. Kirov Military Medical Academy, Ministry of Defence of the Russian Federation

Akademika Lebedeva str., 6, Saint Petersburg, 194044, Russian Federation

${ }^{3}$ Saint Petersburg State Institute of Technology (Technical University)

Moskovskiy prospect, 26, Saint Petersburg, 190013, Russian Federation

Currently, it has been established that the cytokines of the IL-36 family occupy a significant place in the initiation and regulation of the inflammatory process in psoriasis.

Objective: studying the expression level of IL-36y cytokines in the skin of patients with plaque psoriasis. Material and methods. Skin biopsy specimens of 31 patients with plaque psoriasis were studied. The comparison group consisted of 20 biopsy samples of the skin of patients with lichen simplex, discoid eczema, lichen planus, mycosis fungoides (plaque stage). As a control group studied the skin bioptates of 10 healthy people. An immunohistochemical study of the skin was carried out using anti-IL-36y antibodies.

Results. An increase in the relative expression area of IL-36y in the affected skin of patients with plaque psoriasis $(7.4 \%)$ was found, compared with the unaffected areas $(0.10 \%)$ and the control group $(0 \%)$. The expression of IL-36y in the skin of patients with psoriasis in the progressive period $(8.85 \%)$ was 1.42 times higher than in the stationary period of the disease (6.2\%). A strong direct relationship was revealed $(r=0.71)$ between the level of IL-36y expression in the affected skin and the value of the PASI index, a moderate direct relationship between the level of IL-36y expression and epidermal thickness $(r=0.34)$. In the affected skin of psoriasis patients, expressed expression of IL-36y was observed in the upper layers of the epidermis, patients of the comparison group (discoid eczema, lichen simplex, lichen planus, mycosis fungoides) were weak or moderate, in the unaffected areas of the skin of patients with psoriasis and healthy people - weak or absent.

Findings. It was found that the expression of IL-36y in the skin of patients with plaque psoriasis is significantly higher than with other skin diseases. The data obtained allow us to consider this cytokine as a possible diagnostic marker and use it in the differential diagnosis.

Keywords: plaque psoriasis, lichen simplex, lichen planus, discoid eczema, mycosis fungoides, interleukin-36y

Conflict of interest: the authors state that there is no potential conflict of interest requiring disclosure in this article.

For citation: Pashkin A. Yu., Zhukov A. S., Khairutdinov V. R., Belousova I. E., Samtsov A. V., Garabagiou A. V. Studying of the interleukin-36y expression level in the skin of patients with plaque psoriasis. Vestnik Dermatologii i Venerologii. 2019;95(4):31-39. https://doi.org/10.25208/0042-4609-2019-95-4-31-39 
Псориаз - хроническое мультифакториальное иммуноопосредованное воспалительное заболевание кожи. Воспаление в коже больных псориазом рассматривается как аутовоспалительный процесс, ведущую роль в котором играют Т-лимфоциты, дендритные клетки (ДК), кератиноциты и секретируемые ими провоспалительные цитокины: фрактор некроза опухоли- $\alpha$ (TNF $\alpha)$, интерлейкин-1 (IL-1), IL-12, IL-17, IL-22 и IL-23 [1, 2]. В последнее время установлено, что цитокины семейства IL36 также занимают значимое место в инициации и регуляции воспалительного процесса при псориазе [3].

Семейство цитокинов IL-36 включает три агониста:

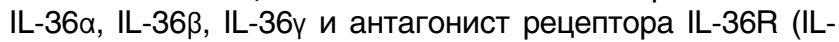
36Ra) [2, 4]. Агонисты, связываясь со специфическим рецептором IL-36R на поверхности иммунных клеток, инициируют их участие в воспалительном процессе посредством активации ядерных транскрипционных фракторов, приводящих к усиленной экспрессии провоспалительных цитокинов и хемокинов [2, 5, 6]. IL-36Ra конкурентно ингибирует связывание агонистов с IL$36 \mathrm{R}$, блокируя внутриклеточные сигнальные пути $[5,7]$. B норме экспрессия цитокинов семейства IL-36 в коже находится на низком уровне, их основным источником являются кератиноциты [8]. Также известно, что клетки Лангерганса, моноциты, макрофраги, ДК, различные субпопуляции T-клеток могут секретировать IL-36 [4, 7, 9].

В большинстве случаев диагноз «псориаз» устанавливают на основании клинической картины, но нередко встречаются пациенты с нетипичными проявлениями заболевания. В таких случаях выполняют диагностическую биопсию кожи с последующим гистологическим исследованием. Патоморфологические изменения при псориазе не имеют строгой специфичности для этого заболевания. Ряд гистологических признаков: равномерный акантоз, папилломатоз, паракератоз, периваскулярные лимфогистиоцитарные инфильтраты в сосочковом слое дермы, - встречается и при других дерматозах: красном плоском лишае (КПЛ), нейродермите, грибовидном микозе (ГМ), хронической экземе, что существенно затрудняет диагностику [10]. Имеются единичные исследования, в которых обнаружена экспрессия МРНК и белка IL-36y в коже больных псориазом, которая не определялась при других воспалительных заболеваниях, таких как атопический дерматит, экзема, КПЛ [11].

Определение уровня экспрессии цитокинов семейства интерлейкина-36ү в коже больных псориазом может не только расширить наши представления об иммунном патогенезе заболевания, но и использоваться в прогностических целях, а также при проведении дифференциальной диагностики с другими дерматозами.

Цель исследования - изучение уровня экспрессии цитокинов IL-36y в коже пациентов с бляшечным псориазом.

\section{Материал и методы}

Группу исследования составил 31 пациент с бляшечным псориазом (мужчин 17 (54,8 \%), женщин 14 (45,2\%), средний возраст 43,7 $\pm 14,7$ года), из них прогрессирующий период заболевания у 16 человек (51,6\%), стационарный период у 15 (48,4\%). Степень тяжести псориаза оценивалась по индексу площади и тяжести псориатических поражений (PASI) [12]. В группы сравнения были включены 20 больных ограниченным нейродермитом (мужчин 13 (65\%), женщин 7 (35\%), средний возраст 32,5 \pm 11,4 года), $20-$ нуммулярной экземой (мужчин 9 (45\%), женщин 11 (55\%), средний возраст 45,1 \pm 17,6 года), $20-$ красным плоским лишаем (мужчин 10 (50\%), женщин 10 (50\%), средний возраст 29,5 \pm 15,2 года), $20-$ грибовидным микозом с бляшечной стадией (мужчин 14 (70\%), женщин 6 (30\%), средний возраст 52,5 $\pm 8,9$ года). У всех пациентов диагноз был подтвержден гистологическим методом исследования. В качестве группы контроля изучали биоптаты кожи 10 здоровых человек (мужчин 4 (40\%), женщин 6 (60\%), средний возраст 38,5 \pm 10,8 года). Все исследуемые подписали «Информированное добровольное согласие на медицинское вмешательство». Получено разрешение независимого этического комитета при ВМедА им. С. М. Кирова.

Объектами морфологического исследования были пораженные и непораженные участки кожи больных бляшечным псориазом, взятые методом инцизионной биопсии. Участки кожи контрольной группы были получены путем иссечения при пластических операциях. При фрормировании групп сравнения использовали архивный биопсийный материал клиники кожных и венерических болезней Военно-медицинской академии.

Применяли гистологический и непрямой иммуногистохимический методы исследования кожи. Из парафиновых блоков кожи готовили срезы толщиной 3 мкм и окрашивали гематоксилином и эозином. Для выявления цитокинов IL-36ү использовались специфические моноклональные античеловеческие антитела anti-IL-36y (Abcom, США, разведение 1:100, pH 6,0), полимерная система визуализации Envision (Dako, Дания) и хромоген диаминобензидин (Dako, Швеция). Патоморфологические изменения в коже изучали с помощью светового микроскопа «Olympus BX-46» (Olympus, Япония), оборудованного цифровой камерой «Olympus DP71», и программного обеспечения «CellA». Уровень экспрессии цитокина IL-36y оценивали в эпидермисе по следующим критериям: 0 - отсутствие экспрессии, 1 - слабый (вы-

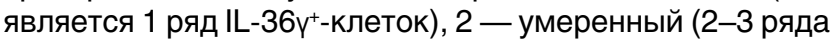

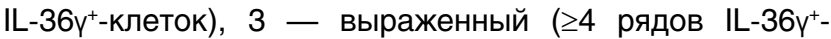
клеток). С целью определения площади окрашенных участков анализировали 3 поля зрения при увеличении ×200 (размеры поля 720×530 мкм), выбранных с учетом наибольшего количества меченых клеток. Результаты оценивали с помощью программного обеспечения «ImageJ 1.48v (USA)». Для количественной оценки экспрессии цитокина IL-36ү был использован показатель относительной площади экспрессии - отношение площади окрашенных IL-36ү' участков к общей площади среза в поле зрения, выраженный в процентах.

Статистическая обработка данных проводилась с использованием программы SPSS 10.0 for Windows (SPSS, Inc). Для сравнения данных между группами применяли U-критерий Манна - Уитни. Достоверными считали различия при $\mathrm{p}<0,05$. Для выявления связи между количественными или качественными показателями применяли коэфрфициент ранговой корреляции Спирмена.

\section{Результаты}

При клиническом обследовании пациентов с бляшечным псориазом были получены следующие результаты: больные с легкой степенью (PASI < 10) составили 11 человек (35,5\%), средней (10 $\leq$ PASI < 20) - 
Таблица 1. Показатели толщины эпидермиса и площади экспрессии IL-36ү в коже больных псориазом и здоровых людей

Table 1. Indicators of the epidermis thickness and the expression area IL-36y in the skin of psoriasis patients and healthy people

\begin{tabular}{ccc}
\hline Группа исследования & $\begin{array}{c}\text { Толщина эпидермиса, мкм } \\
\text { X }\left[\mathrm{x}_{0.25} ; \mathrm{x}_{0.75}\right]\end{array}$ & $\begin{array}{c}\text { Относительная площадь экспрессии IL-36y, \% } \\
\text { X }\left[\mathrm{x}_{0.25} ; \mathrm{x}_{0.75}\right]\end{array}$ \\
\hline Бляшечный псориаз (пораженный участок кожи) $(\mathrm{n}=31)$ & $448,5[379,1 ; 543,4]$ & $7,4[5,6 ; 10,1]$ \\
\hline - прогрессирующий период $(\mathrm{n}=16)$ & $511,4[437,8 ; 558,15]$ & $8,85[4,4 ; 11,9]$ \\
\hline - стационарный период $(\mathrm{n}=15)$ & $382,16[308,9 ; 435,85]$ & $6,2[5,35 ; 7,25]$ \\
\hline $\begin{array}{c}\text { Непораженные участки кожи пациентов } \\
\text { с бляшечным псориазом }(\mathrm{n}=31)\end{array}$ & $70,8[61,4 ; 87,4]$ & $0,10[0 ; 2,15]$ \\
\hline Здоровые лица $(\mathrm{n}=10)$ & $81,3[73,4 ; 86,6]$ & $0[0 ; 0,04]$ \\
\hline
\end{tabular}

Примечание: X - медиана, $X_{025}$ - нижний квартиль, $X_{075}$ - верхний квартиль.

Note: $X$ — median, $x_{0.25}$ - lower quartile, $x_{0.75}$ - upper quartile.

$11(35,5 \%)$, тяжелой (PASI $\geq 20)-9$ (29 \%). Среднее значение PASI $-13,59( \pm 7,25)$.

При гистологическом исследовании выявлено более выраженное увеличение толщины эпидермиса у больных псориазом в прогрессирующем периоде 511,4 [437,8; 558,15] мкм по сравнению со стационарным периодом - 382,16 [308,9; 435,85] мкм $(\mathrm{p}<0,05)$, и значительно выше по сравнению с непораженными участками кожи $70,8[61,4 ; 87,4]$ и группой контроля $81,3[73,4 ; 86,6]$ мкм (р < 0,05) (табл. 1, рис. 2Г). Статистически значимых различий между толщиной эпи- дермиса непораженных участков и группой контроля выявлено не было ( $p>0,05)$.

При непрямом иммуногистохимическом исследовании пораженной кожи больных псориазом во всех исследуемых случаях выявлена экспрессия цитокинов IL-36y в клетках зернистого (при наличии) и шиповатого слоев эпидермиса. Секреции IL-36ү в дерме не обнаружено (рис. 1). Установлено увеличение относительной площади экспрессии IL-36y в пораженной коже пациентов с бляшечным псориазом - 7,4 \% по сравнению с непораженными участками $-0,10 \%$ и группой
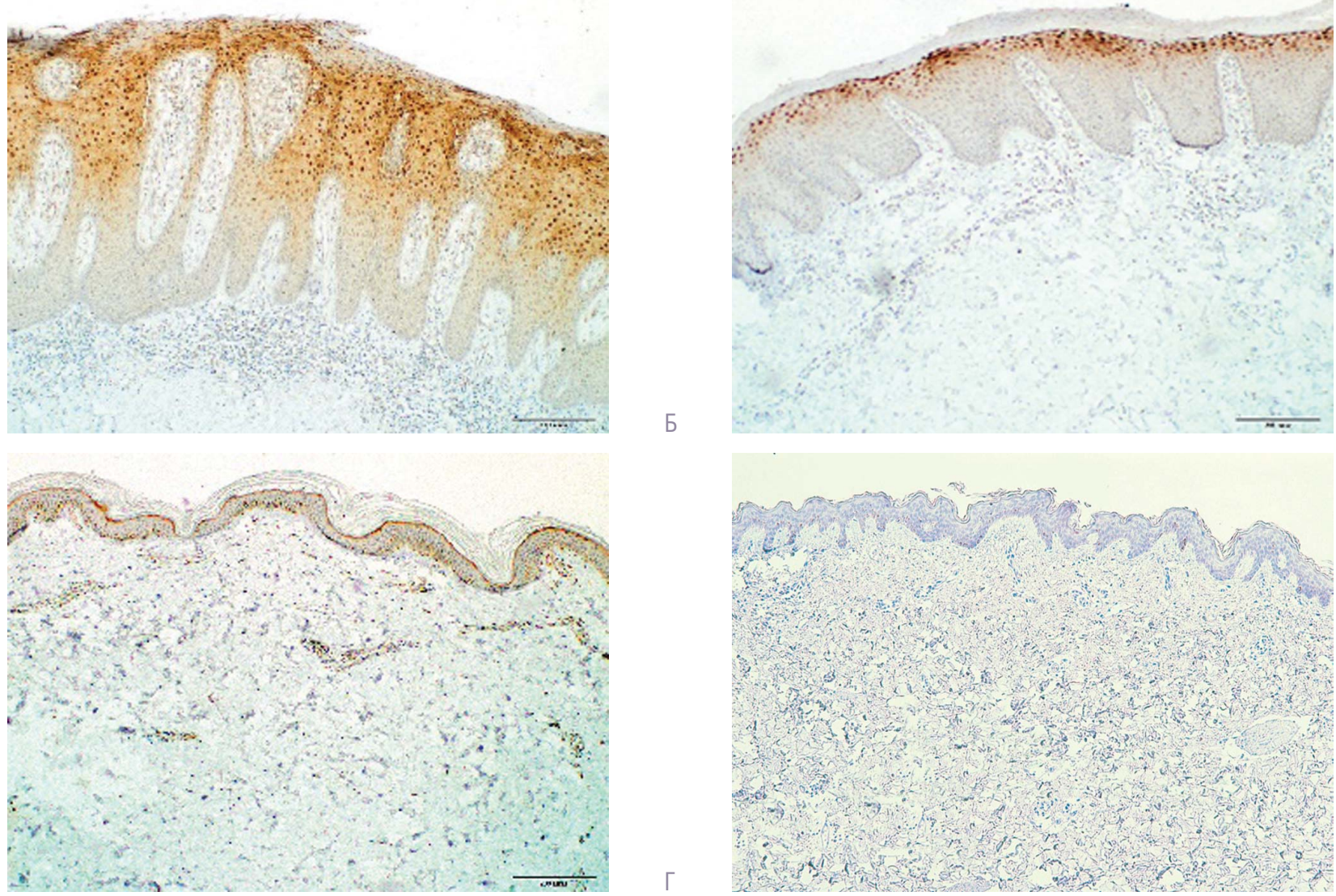

Рис. 1. Непрямое иммуногистохимическое исследование IL-36ү в коже пациентов с бляшечным псориазом в прогрессирующем (А) и стационарном (Б) периодах В сравнении с непораженным участком кожи (В) и группой контроля (Г), увеличение ×100

Fig. 1. Indirect immunohistochemical study of IL-36y in the skin of patients with plaque psoriasis during progressive (A) and stationary (Б) periods in comparison with the unaffected skin area (B) and control group $(\Gamma)$, magn. $\times 100$ 

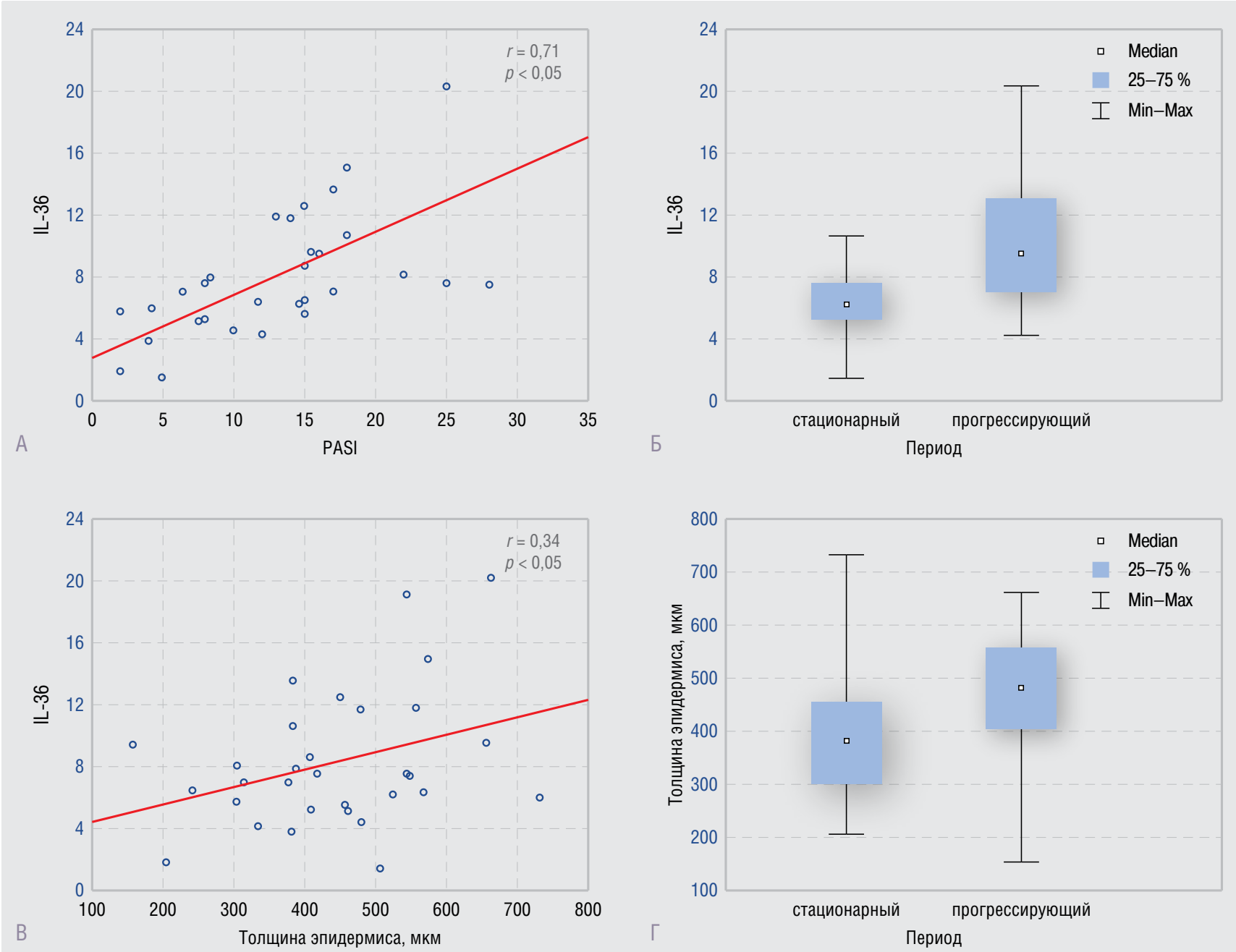

Рис. 2. Корреляционные связи площади экспрессии IL-36y и PASI (A), IL-36ү и толщины эпидермиса (B). Экспрессия IL-36ү и толщина эпидермиса в разные периоды заболевания (Б, Г)

Fig. 2. Correlations between the IL-36y expression area and PASI (A), IL-36y and the epidermis thickness (B). Expression of IL-36y and the epidermis thickness during different disease periods $(Б, \Gamma)$

контроля - 0 \% ( $<<0,05)$. При сравнении уровня экспрессии данного цитокина между непораженными участками кожи больных и группой контроля статистически значимых различий не выявлено (р > 0,05) (табл. 1). Относительная площадь экспрессии IL-36y в коже больных псориазом в прогрессирующем периоде - 8,85 \% была в 1,42 раза выше данного показателя в стационарном периоде заболевания - 6,2 \% (p < 0,05) (рис. 2Б).

При проведении корреляционного анализа у больных псориазом выявлена сильная прямая связь $(r=$ $0,71, p<0,05)$ между уровнем экспрессии IL-36y в пораженной коже и значением индекса PASI (рис. 2A), умеренная прямая связь между уровнем экспрессии IL-36y и толщиной эпидермиса $(r=0,34, p<0,05)$ (рис. 2B).

Проведено гистологическое и иммуногистохимическое исследование биоптатов кожи пациентов с нуммулярной экземой, ограниченным нейродермитом, КПЛ и ГМ. При гистологическом исследовании выявлено увеличение толщины эпидермиса у больных с нуммулярной экземой, ограниченным нейродермитом и КПЛ. Толщина эпидермиса пациентов с ГМ была незначительно увеличена (или нормальная) (рис. 3). Иммуногистохимический анализ показал, что в пораженной коже больных псориазом отмечается выраженная экспрессия IL-36y - в верхних слоях эпидермиса выявляется 4 и более рядов IL-36ү'-клеток, у пациентов группы сравнения (экзема, нейродермит, КПЛ, ГМ) - слабая или умеренная, в непораженных участках кожи больных псориазом и здоровых людей - слабая или отсутствовала $(\mathrm{p}<0,05)$ (табл. 2, рис. 4).

\section{Обсуждение}

Цитокины семейства IL-36 вовлечены в развитие воспалительного процесса при псориазе на самых ранних его этапах. Их роль в патогенезе заболевания заключается в индукции экспрессии кератиноцитами, ДК, Т-лимфоцитами провоспалительных цитокинов и хемокинов [13]. Действие IL-36 на миелоидные ДК приводит к усилению ими секреции IL-1 $\beta$, IL-6, IL-12, IL-18, IL-23, экспрессии на их поверхности молекул главного комплекса гистосовместимости и костимулирующих молекул (CD40, CD83, CD86) [7, 8]. Агонисты семейства IL-36 вызывают секрецию кератиноцитами антимикробных пептидов (ß-дефенсин, белок S100) и матриксных металлопротеиназ, что приводит к миграции Т-лимфоцитов и ДК в зону воспаления [14]. 

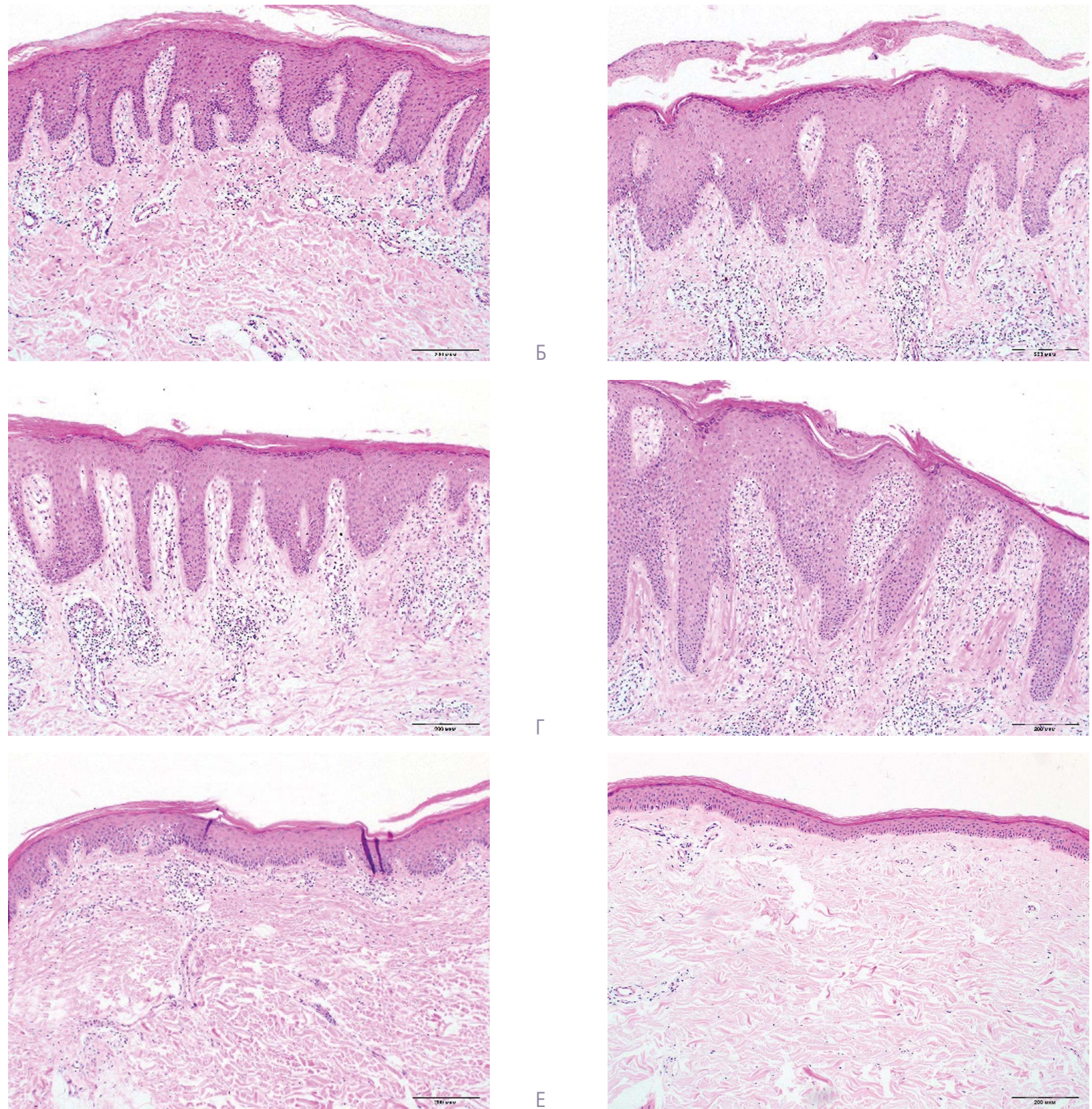

Рис. 3. Гистологическое исследование кожи больных бляшечным псориазом (А), нуммулярной экземой (Б), ограниченным нейродермитом (В), КПЛ (Г), ГМ (Д) и здоровых лиц (Е), окраска гематоксилин-эозин, увеличение ×100. Толщина эпидермиса значительно увеличена у больных псориазом (А), увеличена у больных с нуммулярной экземой (Б), ограниченным нейродермитом (В), КПЛ (Г) и незначительно увеличена (или нормальная) у больных ГМ (Д) и здоровых лиц (Е) Fig. 3. Histological investigation of the skin of patients with plaque psoriasis (A), nummular eczema (Б), limited neurodermatitis (B), lichen planus (Г), mycosis fungoides (Д) and healthy individuals (E); hematoxylin-eosin staining, magn. $\times 100$. The epidermis thickness is significantly increased in patients with psoriasis (A), increased in patients with nummular eczema (Б), limited neurodermatitis (B) and lichen planus (Г); and slightly increased (or normal) in patients with mycosis fungoides (Д) and healthy individuals (E)

Таблица 2. Распределение обследованных больных в зависимости от уровня экспрессии IL-36y в коже

Table 2. Distribution of the examined patients depending on the level of IL-36y expression in the skin

\begin{tabular}{|c|c|c|c|c|c|c|c|}
\hline \multirow[b]{2}{*}{$\begin{array}{c}\text { Уровень } \\
\text { экспрессии IL-36y }\end{array}$} & \multicolumn{2}{|c|}{ Бляшечный псориаз } & \multirow{2}{*}{$\begin{array}{c}\text { Ограниченный } \\
\text { нейродермит } \\
\text { (n= 20) } \\
\text { отн. (\%) }\end{array}$} & \multirow{2}{*}{$\begin{array}{c}\text { Нуммулярная } \\
\text { экзема } \\
(\mathrm{n}=20) \\
\text { отн. (\%) }\end{array}$} & \multirow{2}{*}{$\begin{array}{c}\text { Красный } \\
\text { плоский ли- } \\
\text { шай }(n=20), \\
\text { отн. }(\%)\end{array}$} & \multirow{2}{*}{$\begin{array}{c}\text { Грибовидный } \\
\text { мико3 } \\
(\mathrm{n}=20) \\
\text { отн. }(\%)\end{array}$} & \multirow{2}{*}{$\begin{array}{c}\text { Группа } \\
\text { контроляя } \\
(\mathrm{n}=10), \\
\text { отн. }(\%)\end{array}$} \\
\hline & $\begin{array}{c}\text { Пораженный уча- } \\
\text { сток кожи }(n=31), \\
\text { отн. }(\%)\end{array}$ & $\begin{array}{l}\text { Непораженный } \\
\text { участок кожи } \\
(\mathrm{n}=31), \text { отн. }(\%)\end{array}$ & & & & & \\
\hline Отсутствует & $0(0)$ & $9(29)$ & $4(20)$ & $0(0)$ & $3(15)$ & $15(75)$ & $9(90)$ \\
\hline Слабый & $0(0)$ & $21(68)$ & $14(70)$ & $11(55)$ & $16(80)$ & $4(20)$ & $1(10)$ \\
\hline Умеренный & $0(0)$ & $1(3)$ & $2(10)$ & $8(40)$ & $1(5)$ & $1(5)$ & $0(0)$ \\
\hline Выраженный & $31(100)$ & $0(0)$ & $0(0)$ & $1(5)$ & $0(0)$ & $0(0)$ & $0(0)$ \\
\hline
\end{tabular}



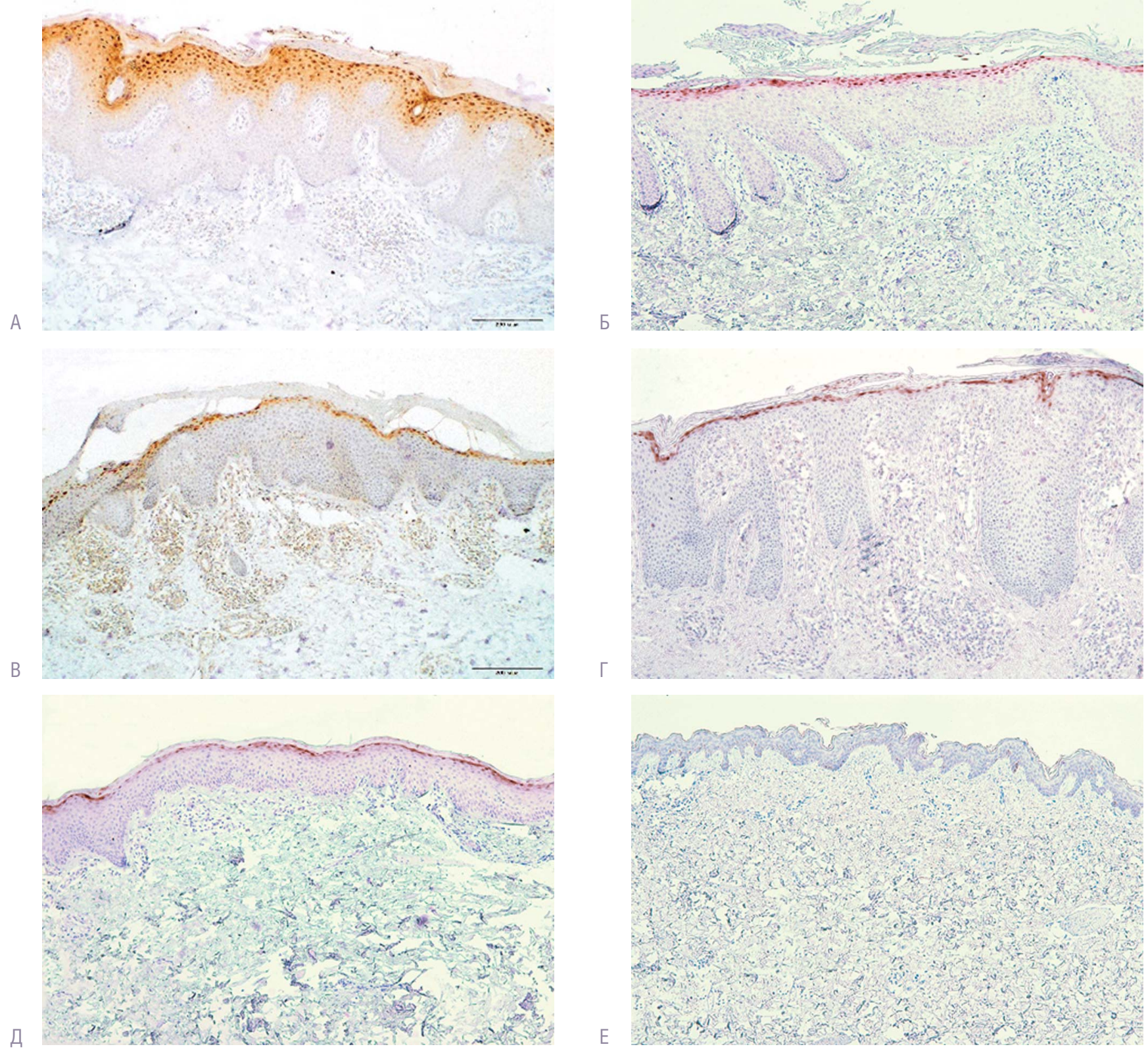

Рис. 4. Непрямое иммуногистохимическое исследование IL-36y в коже пациентов с бляшечным псориазом (А), нуммулярной экземой (Б), ограниченным нейродермитом (B), КПЛ (Г), ГМ (Д) и здоровых лиц (Е), увеличение ×100. В биоптатах кожи пациентов с бляшечным псориазом выявлена выраженная экспрессия IL-36ү (насыщенно-коричневый цвет) в верхних рядах эпидермиса ( $\geq 4$ рядов IL-36ү`-клеток) (A); слабая или умеренная секреция IL-36ү — в коже больных нуммулярной экземой (Б) и ограниченным нейродермитом (В); у больных КПЛ (Г), ГМ (Д) и здоровых лиц (Е) — слабая или отсутствовала

Fig. 4. Indirect immunohistochemical study of IL-36y in the skin of patients with plaque psoriasis (A), nummular eczema (Б), limited neurodermatitis (B), lichen planus (Г),

mycosis fungoides (Д) and healthy individuals (E); magn. $\times 100$. Skin bioptic samples from patients with plaque psoriasis showed: pronounced expression of IL-36y (deep brown colour) in the upper epidermis layers ( $\geq 4$ rows of IL-36y'cells) (A); weak or moderate secretion of IL-36y in the skin of patients with nummular eczema (Б) and limited neuroder-

matitis (B); weak or absent expression of IL-36y in patients with lichen planus (Г), mycosis fungoides (Д) and healthy individuals (E) — weak or absent

Они стимулируют экспрессию CD4+-T-клетками IFNy, IL-4 и IL-17 [15]. В свою очередь, цитокины IL-17A, IFNy, TNF $\alpha$, IL-22 усиливают продукцию кератиноцитами агонистов IL-36 $\alpha, \beta$, ү [16-19]. Появление рецептора IL-36R на поверхности Th0 на ранних стадиях их развития указывает на то, что цитокины IL-36 принимают активное участие в созревании Т-клеток [3, 20]. Блокирование передачи сигнала на уровне IL-36R приводит к уменьшению содержания в коже нейтрофильных гранулоцитов и макрофрагов, значительному снижению экспрессии IL-17A T-клетками и разрешению псориатических высыпаний [21].
В нашем исследовании мы обнаружили выраженную экспрессию цитокина IL-36ү в пораженной коже пациентов с бляшечным псориазом по сравнению с непораженными участками кожи и группой контроля. Наиболее высокий уровень IL-36ү отмечался у пациентов в прогрессирующем периоде заболевания. Корреляционный анализ выявил сильную прямую связь между уровнем экспрессии IL-36ү в области псориатических высыпаний и степенью тяжести заболевания.

C помощью метода непрямого иммуногистохимического исследования мы определили уровень 
экспрессии IL-36y в коже больных ограниченным нейродермитом, нуммулярной экземой, КПЛ и ГМ. Установлено, что экспрессия IL-36ү в коже пациентов с бляшечным псориазом значительно выше, чем при других дерматозах. Полученные данные позволяют рассматривать этот цитокин в качестве возможного диагностического маркера и использовать его при проведении дифференциальной диагностики.

\section{Участие авторов:}

Анализ и интерпретация данных - Пашкин А. Ю., Жуков А. С. Написание статьи - Пашкин А. Ю.

Разработка концепции и дизайна - Хайрутдинов В. Р.

Обоснование рукописи и проверка критически важного интеллектуального содержания - Белоусова И. Э.

Окончательное утверждение на представление рукописи - Самцов А. В., Гарабаджиу А. В.

\section{Литература/References}

1. Хайрутдинов В. Р., Белоусова И. Э., Самцов А. В. Иммунный патогенез псориаза. Вестник дерматологии и венерологии. 2016;(4):20-26. [Khairutdinov V. R., Belousova I. E., Samtsov A. V. Immune pathogenesis of psoriasis. Vestnik Dermatologii i Venerologii. 2016;(4):20-26. (In Russ.)]

2. Пашкин А. Ю., Воробьева Е. И., Хайрутдинов В. Р, Белоусова И. Э., Самцов А. В., Гарабаджиу А. В. Роль цитокинов семейства интерлейкина-36 в иммунопатогенезе псориаза. Медицинская иммунология. 2018;20(2):163-170. [Pashkin A. Y., Vorobyeva E. I., Khairutdinov V. R., Belousova I. E., Samtsov A. V., Garabagiou A. V. The role of cytokines of interleukin 36 family in immunopathogenesis of psoriasis. Medical Immunology (Russia). 2018;20(2):163-170. (In Russ.)]

3. Vigne S., Palmer G., Martin P. et al. IL-36 signaling amplifies Th1 responses by enhancing proliferation and Th1polarization of naive CD4+ T cells. Blood. 2012;120(17):3478-3487.

4. Boutet M. A., Bart G. Distinct expression of interleukin (IL)-36 $\alpha, \beta$ and $\gamma$, their antagonist IL-36Ra and IL-38 in psoriasis, rheumatoid arthritis and Crohn's disease. Clin Exp Immunol. 2016;184(2):159-173.

5. Towne J. E., Garka K. E., Renshaw B. R., Virca G. D., Sims J. E. Interleukin (IL)-1F6, IL-1F8, and IL-1F9 signal through IL-1Rrp2 and IL1RAcP to activate the pathway leading to NF-kappaB and MAPKs. J Biol Chem. 2004;279(14):13677-13688.

6. Günther S., Sundberg E. J. Molecular determinants of agonist and antagonist signaling through the IL-36 receptor. J Immunol. 2014;193(2):921-930.

7. Gabay C., Towne J. E. Regulation and function ofinterleukin-36 cytokines in homeostasis and pathological conditions. J Leukoc Biol. 2015;97(4):645-652.

8. Buhl A. L., Wenzel J. Interleukin-36 in infectious and inflammatory skin diseases. Front Immunol. 2019;10:1162.

9. Dietrich D., Gabay C. IL 36 has proinflammatory effects in skin but not in joints. Nat Rev Rheumatol. 2014;10(11):639-640.

10. Chau T., Parsi K. K., Ogawa T., Kiuru M., Konia T., Li C.-S. et al. Psoriasis or not? Review of 51 clinically confirmed cases reveals an expanded histopathologic spectrum of psoriasis. Journal of Cutaneous Pathology. 2017;44(12):1018-1026.
11. D’Erme A. M., Wilsmann-Theis D., Wagenpfeil J. et al. IL36gamma (IL1F9) is a biomarker for psoriasis skin lesions. J Invest Dermatol. 2015;135(4):1025-1032.

12. Fredriksson T., Pettersson U. Severe psoriasis - oral therapy with a new retinoid. Dermatologica. 1978;157(4):238-244.

13. Towne J. E., Renshaw B. R., Douangpanya J., Lipsky B. P., Shen M., Gabel C. A. et al. Interleukin-36 (IL-36) ligands require processing for full agonist (IL-36 alpha, IL-36 beta, and IL- 36 gamma) or antagonist (IL-36Ra) activity. J Biol Chem. 2011;286(49):42594-42602.

14. Foster A. M., Baliwag J., Chen C. S. et al. IL-36 promotes myeloid cell infiltration, activation, and inflammatory activity in skin. J Immunol. 2014;192(12):6053-6061

15. Vigne S., Palmer G., Lamacchia C., Martin P., Talabot-Ayer D., Rodriguez $\mathrm{E}$. et al. IL-36R ligands are potent regulators of dendritic and T cells. Blood. 2011;118(22):5813-5823.

16. Carrier Y, Ma H. L., Ramon H. E., Napierata L., Small C., 0'Toole M. et al. Inter-regulation of Th17 cytokines and the IL-36 cytokines in vitro and in vivo: implications in psoriasis pathogenesis. J Invest Dermatol. 2011;131(12):2428-2437.

17. Friedrich M., Tillack C., Wollenberg A., Schauber J., Brand S. IL36 gamma sustains a proinflammatory self-amplifying loop with IL17C in anti TNF induced psoriasiform skin lesions of patients with Crohn's disease. Inflamm Bowel Dis. 2014;20(11):1891-1901.

18. Johnston A., Fritz Y., Dawes S. M. et al. Keratinocyte overexpression of IL-17C promotes psoriasiform skin inflammation. J Immunol. 2013;190(5):2252-2262.

19. Milora K. A., Fu H., Dubaz O., Jensen L. E. Unprocessed Interleukin-36a Regulates Psoriasis-Like Skin Inflammation in Cooperation with Interleukin-1. J Invest Dermatol. 2015;135(12):2992-3000.

20. Muhr P., Zeitvogel J., Heitland I., Werfel T., Wittmann M. Expression of interleukin (IL)-1 family members upon stimulation with IL-17 differs in keratinocytes derived from patients with psoriasis and healthy donors. Br J Dermatol. 2011;165(1):189-193.

21. Tecchio C., Micheletti A., Cassatella M. A. Neutrophil-derived cytokines: facts beyond expression. Front Immunol. 2014;5:508. 


\section{Информация об авторах}

Алексей Юрьевич Пашкин - врач-дерматовенеролог, начальник отделения 3-го военного госпиталя войск национальной гвардии Российской Федерации; тел.: +7 (911) 091-83-73; e-mail: alek-pashkin@yandex.ru

Александр Сергеевич Жуков - к.м.н., докторант кафедры кожных и венерических болезней Военно-медицинской академии им. С. М. Кирова Министерства обороны Российской Федерации; е-mail: doctor-vma@mail.ru

Владислав Ринатович Хайрутдинов ${ }^{*}$ - д.м.н., доцент, доцент кафедры кожных и венерических болезней Военно-медицинской академии им. С. М. Кирова Министерства обороны Российской Федерации; тел.: +7 (905) 205-75-99; e-mail: haric03@list.ru

Ирена Эдуардовна Белоусова - д.м.н., доцент, профессор кафедры кожных и венерических болезней Военно-медицинской академии им. С. М. Кирова Министерства обороны Российской Федерации; тел.: +7 (921) 965-12-18; e-mail: irena.belousova@mail.ru

Алексей Викторович Самцов - д.м.Н., профессор, заведующий кафредрой кожных и венерических болезней Военно-медицинской академии им. С. М. Кирова Министерства обороны Российской Федерации; тел.: +7 (812) 271-87-81; e-mail: avsamtsov@mail.ru

Александр Васильевич Гарабаджиу - д.Х.н., профессор, проректор по научной работе Санкт-Петербургского государственного технологического института (технического университета); тел.: +7 (921) 938-20-60; e-mail: gar-54@mail.ru

\section{Information about the authors}

Alexey Yu. Pashkin — Dermatovenerologist, Head of the Department, The 3d Military Hospital, National Guard Forces of the Russian Federation; tel.: +7 (911) 091-83-73; e-mail: alek-pashkin@yandex.ru

Alexander S. Zhukov - Cand. Sci. (Med.), Doctoral Student, Department of Skin and Sexually Transmitted Diseases, S. M. Kirov Military Medical Academy, Ministry of Defence of the Russian Federation; e-mail: doctor-vma@mail.ru

Vladislav R. Khairutdinov* — Dr. Sci. (Med.), Assoc. Prof., Department of Skin and Sexually Transmitted Diseases, S. M. Kirov Military Medical Academy, Ministry of Defence of the Russian Federation; tel.: +7 (905) 205-75-99; e-mail: haric03@list.ru

Irena E. Belousova - Dr. Sci. (Med.), Assoc. Prof., Prof., Department of Skin and Sexually Transmitted Diseases, S. M. Kirov Military Medical Academy, Ministry of Defence of the Russian Federation; tel.: +7 (921) 965-12-18; e-mail: irena.belousova@mail.ru

Alexey V. Samtsov - Dr. Sci. (Med.), Prof., Head of the Department of Skin and Sexually Transmitted Diseases, S. M. Kirov Military Medical Academy, Ministry of Defence of the Russian Federation; tel.: +7 (812) 271-87-81; e-mail: avsamtsov@mail.ru

Alexander V. Garabagiou - Dr. Sci. (Chemistry), Prof., Vice-Rector for Scientific Work, Saint Petersburg State Institute of Technology (Technical University); tel.: +7 (921) 938-20-60; e-mail: gar-54@mail.ru 